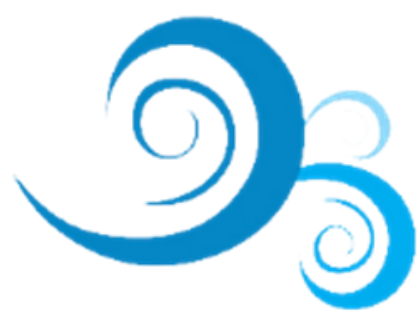

\title{
O PROGRAMA CALHA NORTE COMO PRÁTICA ESPACIAL DO ESTADO BRASILEIRO (1985-2018): PERSPECTIVAS DE AMAZÔNIA E DISCURSO DE PRECARIEDADE COMO POLÍTICA PÚBLICA
}

\author{
LEONARDO ULIAN DALL EVEDOVE \\ Professor adjunto no Curso de Relações Internacionais da Universidade \\ Federal de Roraima (UFRR), Boa Vista (RR), Brasil. \\ ORCID: https://orcid.org/0000-0002-3996-5171 \\ leodallevedove@gmail.com
}

\begin{abstract}
RESUMO: Neste artigo, desenvolvemos análise crítica do Programa Calha Norte (PCN) entre os anos 1985 e 2018, a partir do conceito de práticas espaciais. O PCN, fundado em 1985 como um projeto ligado ao Conselho de Segurança Nacional, passou por diversas mudanças institucionais até chegar ao fim do período em análise inserido no Ministério da Defesa. Considerado pelo governo brasileiro como um Programa Social da Defesa desde 2012, configura-se desde sua fundação, como uma política de infraestrutura civil e militar, e hoje abrange os estados da região norte, Maranhão, Mato Grosso e Mato Grosso do Sul. Inicialmente, compusemos uma revisão institucional do programa a partir de documentos fundamentais e de bibliografia temática especializada. A crítica do trabalho está ancorada no conceito de práticas espaciais, a partir da leitura de Henri Lefebvre e Bertha Becker, que percebem o espaço como uma relação política subjetiva, por meio da qual o Estado se cria e justifica a partir da interação com outros atores sociais e políticos. Em nossa leitura, o PCN concebe o ambiente amazônico que abrange como precário, com vazio de poder, e afirma competência e privilégio das instituições militares em continuar promovendo uma noção unilateral de desenvolvimento.
\end{abstract}

PALAVRAS-CHAVE: Programa Calha Norte; práticas espaciais na Amazônia; política de defesa.

\section{THE CALHA NORTE PROGRAM AS A SPATIAL PRACTICE BY THE BRAZILIAN STATE (1985-2018): PUBLIC POLICY, DISCOURSES OF PRECARIOUSNESS AND PERSPECTIVES OVER THE AMAZON REGION}

\begin{abstract}
The article develops a critical analysis of the Calha Norte Program (CNP) based on the concept of spatial practices between 1985 and 2018. Founded in 1985, CNP was then part of the Brazilian National Security Council. It underwent several institutional changes before being aggregated into the Ministry of Defense in 1999. Being labeled by Brazilian White Papers as a Defense Social Program from 2012 on, CNP is an infrastructural program with military and civilian branches, covering all seven States of the North region of the country plus the States of Maranhão, Mato Grosso, and Mato Grosso do Sul. We begin the article reviewing critical documents and specialized texts related to the institutional policies created by the program. The theoretical approach is grounded in the concept of spatial practice, formulated by Henri Lefebvre and firstly applied to the Amazonian context by geographer Bertha Becker. They have seen space as a subjective political relation in which the State produces itself from the interaction with other socio-political agencies. From our point of view, CNP conceives the Amazonian environment as rudimentary and within a power vacuum, responding to that by affirming that military institutions are uniquely competent to bring a one-dimensional development program.
\end{abstract}

KEYWORDS: Calha Norte Program; spatial practices in the Amazon; defense policy. 


\section{EL PROGRAMA CALHA NORTE COMO PRÁCTICA ESPACIAL DEL ESTADO BRASILEÑO (1985-2018): PERSPECTIVAS DE LA AMAZONÍA Y DISCURSO DE PRECARIEDAD COMO POLÍTICA PÚBLICA}

RESUMEN: En este artículo desarrollamos un análisis crítico del Programa Calha Norte (PCN), entre los años 1985 y 2018, basado en el concepto de prácticas espaciales. EI PCN, creado en 1985 como un proyecto vinculado al Consejo de Seguridad Nacional de Brasil, de la dictadura, y después de haber sufrido una serie de cambios institucionales llegó hasta 1999 como parte del Ministerio de la Defensa. El programa está diseñado por el gobierno brasileño como un Programa Social de la Defensa desde el año 2012 y se ha configurado desde su creación como una política de infraestructura civil y militar. Geográficamente cubre los estados de la región norte del país, además de Maranhão, Mato Grosso y Mato Grosso do Sul. Inicialmente, hicimos una revisión institucional del programa a partir de documentos fundamentales y bibliografía temática especializada. La crítica presentada se basa en el concepto de prácticas espaciales, a partir de la lectura de Henri Lefebvre y Bertha Becker, quienes perciben el espacio como una relación política subjetiva, a través de la cual el Estado se crea y se justifica a través de la interacción con otros actores sociales y políticos. En nuestra lectura, el PCN concibe el ambiente amazónico como precario, dónde hay un vacío de poder político, y afirma la competencia y el privilegio de las instituciones militares para seguir impulsando una noción unilateral de desarrollo.

PALABRAS CLAVE: Programa Calha Norte; prácticas espaciales en la Amazonía; política de defensa.

\section{Introdução}

O propósito deste artigo é problematizar política e teoricamente o Programa Calha Norte (PCN) como prática espacial do Estado brasileiro, uma vez que aquele se caracteriza por uma política pública do Ministério da Defesa do Brasil para a Amazônia. O conceito de prática espacial e o aparato teórico a ele relacionado serão abordados a partir do pensamento de Henri LeFebvre, trazidos também pela geógrafa Bertha Becker ao estudar a região amazônica em diversos trabalhos.

Trata-se de um artigo de análise documental crítica do desenvolvimento institucional do PCN, composto da descrição de suas características políticas gerais, principais objetivos e ações desde sua fundação (1985) e o último mandato presidencial completo no Brasil (2018). Serão priorizados aqueles documentos que estiverem relacionados a sua caracterização, fundação e mudanças importantes em seu percurso histórico.

As linhas gerais deste trabalho estão traçadas em torno de produzir uma leitura da Amazônia que questione seu lugar de objeto de uma política espacial praticada pelo Estado brasileiro. O tema se desdobrou de um estudo da política de defesa brasileira, focado nos chamados Programas Sociais da Defesa, dos quais faz parte o PCN. Originalmente, a justificativa deste programa era atender uma área geográfica 
específica, a calha norte dos rios Solimões e Amazonas, trazendo a questão do espaço como uma determinante de existência. Surgem daí inquietações que este artigo pretende explorar, a saber, a importância do espaço enquanto conceito e sua particularidade quando determinado por esta política pública. Ambas as questões são compreendidas como fundamentos do PCN, e, prospectivamente, vistas como suas condicionantes.

Depois de expormos o argumento deste artigo, da apresentação do PCN e de sua inserção no contexto amazônico, nesta seção, passamos à segunda parte. Nela, expomos o histórico institucional do programa, situando-o no conjunto de documentos, órgãos oficiais e ações que empreende. Na terceira parte, trabalhamos o aparato conceitual de Lefebvre sobre o espaço, sua produção e as práticas espaciais, seguida da exposição da leitura de Becker associando esse sistema ao espaço amazônico. A quarta parte associa a descrição histórica do PCN, feita na segunda seção do texto, e os elementos teóricos, trabalhados na terceira seção, com o objetivo de avaliar o argumento do artigo. Por fim, trazemos uma leitura conclusiva e discutimos o potencial de se estudar o PCN e a região amazônica a partir da perspectiva trabalhada.

\section{O Projeto Calha Norte no contexto amazônico}

O PCN é definido atualmente pelo órgão que o abriga, o Ministério da Defesa, como um financiador de obras de infraestrutura civil e militar. Numa referência ao tipo de ações que empreende, relata o Ministério que o programa abrange infraestruturas nas áreas de defesa, educação, esporte, segurança pública, saúde, assistência social, transportes e desenvolvimento econômico. Ele faz parte dos chamados Programas Sociais da Defesa (PSD), ao lado do Projeto Rondon, o Programa Forças no Esporte, o Projeto Soldado Cidadão e as Ações Subsidiárias e Complementares (BRASIL. MINISTÉRIO DA DEFESA, 2020).

O Programa, que já foi chamado de Projeto Calha Norte, foi fundado em 1985 em meio a várias controvérsias. Sua abrangência geográfica e finalidade originais estão expressas no título do documento sigiloso que lhe deu origem: Desenvolvimento e segurança na região das calhas dos rios Solimões e Amazonas - Projeto Calha Norte (BRASIL. CONSELHO DE SEGURANÇA NACIONAL, 1985). De acordo com Diniz (1994), sua origem era secreta até vir ao conhecimento público por meio de uma 
comissão mista parlamentar de inquérito, instaurada a partir de notícias do jornal $\mathrm{O}$ Estado de S. Paulo, em 1986. Ainda de acordo com o autor, o projeto foi gestado pelo Conselho de Segurança Nacional, a partir de um trabalho conjunto de diversas agências do governo à época, entre elas a Secretaria de Planejamento, Ministério das Relações Exteriores e Ministério do interior (DINIZ, 1994, p. 88).

O conceito do programa estava pautado, de acordo com documento que criou a comissão de trabalho, no binômio segurança e desenvolvimento. No que cabe à questão da segurança, a perspectiva era estabelecida por preocupações do Exército e tinham como objeto a baixa cooperação política bilateral entre países amazônicos, baixa presença militar na Amazônia brasileira, marcos limítrofes danificados ou inexistentes, a política indigenista e a carência generalizada de infraestruturas civis, como estradas, abastecimento de energia elétrica, integração com polos de desenvolvimento econômico e carência de recursos sociais básicos (DINIZ, 1994; BRASIL. CONSELHO DE SEGURANÇA NACIONAL, 1985).

O binômio segurança e desenvolvimento presente no documento que inspirou o então Projeto Calha Norte é fundamental enquanto diretriz de política pública. Em primeiro lugar, estabelece elemento forte de continuidade com uma tônica do período militar, que teve nestes conceitos uma das bases de toda a atividade governamental. Em segundo lugar, afirma a direção da atividade política, social, econômica e cultural do Estado brasileiro em torno da interiorização do território nacional, mantendo no espaço amazônico e fronteiriço seu horizonte. Em consequência disso, coloca esses espaços em evidência, chamando atenção deste artigo sobre qual seria a concepção fundamental que esse projeto, tornado programa quase vinte anos depois de sua fundação, e vigente até a atualidade.

Este artigo busca conhecer a progressão política e institucional do PCN, avaliando padrões de continuidade e ruptura desde sua fundação; compreender as relações de poder entre o Estado brasileiro e a área de interesse do PCN, em seu caráter amazônico e fronteiriço, mediadas pelo conceito de espaço; e avaliar os atributos assumidos pelo governo federal e seus órgãos envolvidos na formulação e execução do programa, como foco para suas práticas espaciais.

2 A representação do espaço amazônico nos documentos fundamentais do Programa Calha Norte e em suas principais mudanças no período estudado 
Com o intuito de apresentar a progressão institucional do PCN, partimos de alguns documentos basilares que serão apresentados a seguir, realçando referências a categorias relativas ao espaço, especialmente naquelas que se situem no corpus teórico da geografia, da geopolítica, da ciência política, de estudos ambientais ou estratégicos. Embora isso possa parecer demasiado eclético, a discussão a partir de Lefebvre a ser realizada posteriormente articulará essas abordagens. Reforçamos que o objetivo deste artigo é compreender a visão de espaço que embasou o desenho político do programa, e, portanto, o relato das ações, avaliação de atividades, análise de orçamento, serão feitas de forma dirigida.

Como exposto acima, o PCN nasceu como um projeto sigiloso, destinado à calha norte dos rios Solimões e Amazonas. O retrato do espaço esboçado no documento é apresentado em uma seção intitulada diagnóstico, estabelecendo aí uma relação de observador e observado, na qual a posição do observador situa-se anteriormente ou fora da circunscrição do quadro observado. Em seguida, seguem-se considerações sobre a quantificação do território abrangido pelo projeto, conceito contido no universo espacial. Aqui entendemos território como "o espaço definido e delimitado por e a partir de relações de poder" (SOUZA, 2000, p. 78). Tratava-se, de acordo com o documento, de $14 \%$ do total nacional e $24 \%$ da Amazônia Legal. Além disso, o componente físico do espaço é subdividido em três tipos de perfis, o fronteiriço, o interiorano e o das zonas ribeirinhas, que pedem pela ação estatal de maneira especializada (BRASIL. CONSELHO DE SEGURANÇA NACIONAL, 1985, p. $1-2)$.

Quanto ao componente humano do espaço, o documento afirma haver ali "rudimentarismo de suas formas produtivas", pequenas populações circunscritas às capitais de estados e territórios administrativos, concentração de reservas indígenas em faixas de fronteira, para as quais se recomenda uma revisão das políticas indigenistas (BRASIL. CONSELHO DE SEGURANÇA NACIONAL, 1985, p. 1).

$O$ documento apresenta então estratégias de ação, vinculadas ao diagnóstico geral, vistas como aspectos de segurança nacional. Em primeiro lugar, defende que as relações bilaterais e a integração sejam incrementadas com países da região, uma vez que veem o país como em "nível mais alto de desenvolvimento econômico" e que por isso, não haveria razão para temor. O texto deixa claro que as medidas propostas 
de incentivo ao comércio, à cooperação técnica, revisão do Tratado de Cooperação Amazônica (TCA), ações conjuntas contra no narcotráfico, e de reforço consular na faixa de fronteira são desejáveis porque assimétricas em favor do Brasil (BRASIL. CONSELHO DE SEGURANÇA NACIONAL, 1985, p. 3).

Uma segunda recomendação do documento é a antecipação do então previsto aumento da presença militar na Calha Norte, com aporte de verbas específicas para a construção ou o recondicionamento de equipamentos militares da defesa, como pelotões de fronteira, aeródromos, embarcações e de vias de navegação. Neste quesito ainda é apresentada a cooperação com outras agências do Estado, que seria aumentada pela melhor estrutura de defesa, como vetor de desenvolvimento da região.

A terceira recomendação preocupa-se com os marcos dos limites geográficos do Brasil com os países vizinhos, evidenciando certa visão da fronteira, na qual o marcos físico tem importância e são fontes de preocupação.

A quarta recomendação consiste em adequar a política indigenista. Os componentes assumidos objetivamente sobre o tema referem-se ao Brasil ter sido criticado internacionalmente sobre o tratamento dado às populações indígenas e de que a revisão da política deve ser feita a partir de "uma experiência de campo intensificada". O termo utilizado para retratar a situação é sensibilidade, e a percepção de que os planejadores do projeto assumem uma baixa presença militar na região é marcante. Outro complicador apontado pelos propositores do projeto é a presença de parte dessas pessoas em faixas de fronteira Brasil. (CONSELHO DE SEGURANÇA NACIONAL, 1985, p.4).

O quinto e último ponto foco de atenção do $\mathrm{PCN}$ está centrado em estruturas de integração nacional e desenvolvimento econômico. O próprio documento assume que não houve tempo de formular detalhadamente as ações a serem implementadas. Mas é possível afirmar que este projeto, no qual se destaca a participação militar em todas as instâncias, da deliberação política, passando pelo planejamento e chegando até a execução, assume que esse componente militar será um vetor determinante da integração e do desenvolvimento econômico da Calha Norte, o que não seria feito sem atingir outras áreas da Amazônia (BRASIL. CONSELHO DE SEGURANÇA NACIONAL, 1985, p. 4-5). 
As primeiras ações previstas pelo projeto, vistas como urgentes à época, indicavam basicamente o aumento da presença militar e da restauração/construção de marcos limítrofes. Cada uma está atrelada a uma ameaça percebida, sendo uma delas os lanomâmis, com referências a um ideal de construção de Estado pela etnia. Somam-se a ela a atividade criminosa transnacional, na região da Cabeça do Cachorro, eventuais acirramentos de disputas territoriais entre Venezuela e Guiana, e, por fim, uma baixa presença do ente militar em outras localidades fronteiriças do Brasil. Na seção das justificativas do PCN, a efetivação da atividade consular em faixa de fronteira é vista como vetor de desenvolvimento e "vivificação de fronteiras" [sic] (BRASIL. CONSELHO DE SEGURANÇA NACIONAL, 1985, p. 5, 6 e 8).

Para que se conclua a descrição do documento, é necessário informar que ele se constitui ainda de detalhamento das ações do viés militar do Programa, já que não é composto exclusivamente dele, com tabelas orçamentárias e sugestão de responsabilidades de planejamento e execução. Há previsão de incremento financeiro a atividades da Fundação Nacional do Índio (FUNAI), do qual grande parte das obras é para uso de agências governamentais e das Forças Armadas. Ao fim dos elementos que interessam a este artigo, cabe mencionar um conjunto de valores a ser observado na consecução das ações descritas nas seções anteriores do documento, como viabilidade econômica, justiça social, ecologia, respeito às culturas amazônicas, melhoria da qualidade de vida. Destaca-se que se devem "valorizar a cultura das sociedades indígenas, com o propósito de integrá-las progressiva e harmonicamente à comunhão nacional" (BRASIL. CONSELHO DE SEGURANÇA NACIONAL, 1985, p. 13-33).

Eugênio Diniz (1994) interpreta que as duas principais vertentes do PCN eram, à época de sua elaboração, a militar e a indigenista. Além disso, entende o autor que houve um processo de aproximação entre a ala militar e as agências civis responsáveis pela política indigenista, o que foi muito criticado por entidades da sociedade civil e intelectuais especializados. Parte das críticas da sociedade civil se situava em alegada priorização dada pelo Projeto na defesa de recursos minerais do solo amazônico, vistos como alvos da cobiça internacional, em detrimento de políticas centradas na defesa dos povos indígenas. No campo das disputas por poder e recursos naturais, estavam subjacentes o conflito leste oeste, reforçado pela 
aproximação do regime do Suriname com o cubano (DINIZ, 1994, p. 89, Procópio, 2007, p. 100-101).

O autor vai além e afirma que "a questão indígena sempre esteve, na história brasileira, intimamente associada à construção do Estado e a problemas militares", informando que a FUNAI, naquele momento, era um apêndice do PCN. O Projeto, de acordo com ele, significou um contraponto a outra linha de política indigenista, centrada no Programa de Proteção de Meio Ambiente e às Comunidades Indígenas (PMACI), que sendo mais horizontalizado em relação às demandas dos povos indígenas, foi compensação imposta pelo Banco Interamericano de Desenvolvimento (BID) para financiamentos concedidos ao Brasil (DINIZ, 1994, p. 94-95, 111, 113).

As diversas críticas que o PCN acumulou, especialmente no que tange à questão indígena e à escassez de recursos que atingiu o Estado brasileiro a partir dos anos 1990, fez com que entrasse em estado de relativa paralisia, especialmente a partir do governo Fernando Collor de Mello, e se estendendo por toda a década de 1990 (SILVA, 2007, p. 70). Este presidente estaria associado a maior porosidade às reivindicações locais e internacionais de maior respeito ao meio ambiente, o que o distanciava da perspectiva soberanista do período anterior (COSTA SILVA, 2004, p. $55)$.

O início da década de 1990 viu chegar o fim da Guerra Fria, aumentarem as pressões internacionais sobre a gestão brasileira das questões ambientais e a mudança de postura do Brasil frente ao tema, marcado pela Conferência do Rio, em 1992. Esses elementos são possíveis explicações para a decisão de Itamar Franco, sucessor de Collor após processo de impeachment, na política de defesa para a Amazônia, ter preferido dar mais atenção a outro projeto, o do Sistema de Proteção da Amazônia (SIPAM), dentro do qual seria gestado o Sistema de Vigilância da Amazônia (SIVAM) (COSTA SILVA, 2005, p. 56-57).

Administrativamente, $\mathrm{PCN}$ foi gerido de maneira interministerial $\mathrm{e}$ interagências, ligado diretamente à Presidência da República, contando sempre com a direção militar. Nascimento (2005) faz um relato detalhado das características históricas e institucionais do projeto, e informa que sua cúpula já foi composta por três ministérios civis e três militares, dentre os últimos o Ministério do Exército, que desempenhava a direção. Em momentos posteriores, o projeto passou por secretarias especiais da presidência relacionadas à defesa, a assuntos estratégicos até que fosse 
alocado internamente ao Ministério da Defesa (MD), a partir de 1999. (NASCIMENTO, 2005, p. 177).

Durbens Nascimento (2005) avaliou os orçamentos do PCN ao longo dos anos 1986-2002, e afirma que, do total investido nesse intervalo de tempo, $77,33 \%$ ocorreram nos períodos Sarney, Collor e Franco, e 22,67\% ocorreram no período Cardoso (NASCIMENTO, 2005, p. 253). Essa informação é relevante por conta de ser referência à prioridade dada pelos governos em questão com o programa, associada a outros fatores contextuais, em matérias econômicas, políticas e sociais.

O visível decréscimo de investimentos do mandato de Fernando Henrique Cardoso no PCN, no entanto, teve nuances. No fim de seu segundo mandato se concentrou a maior parte dos aportes financeiros ao projeto, bem como começaram a ser realizados estudos para revigorá-lo. Um dos resultados foi o de converter o Projeto Calha Norte em Programa Calha Norte em 2000 (NASCIMENTO, 2005, p. 252).

Além da fundação do Ministério da Defesa, em 1999, a política de defesa brasileira, a partir de Fernando Henrique Cardoso, passará a contar com documentos fundamentais da área, que a acompanhará até o fim do período abrangido por este artigo. Contidos neles estão desde a definição das linhas gerais área, passando pelo estabelecimento de metas, descrição do aparato burocrático da defesa, divisão de papéis contidos em todas as atribuições constitucionais das Forças Armadas e suas tarefas subsidiárias e administrativas. Estes documentos seriam a Política de Defesa Nacional (PDN), de 1996, lançada por Fernando Henrique Cardoso; a Política de Defesa Nacional e a Estratégia Nacional de Defesa (END), lançadas respectivamente em 2005 e 2008, por Luiz Inácio Lula da Silva; o Livro Branco da Defesa Nacional (LBDN), lançado por Dilma Rousseff, em 2012; e o Livro Branco da Defesa Nacional, lançado por Michel Temer em 2016.

O vetor amazônico da política de defesa brasileira se confirma como um de seus pilares, progressivamente, em todos esses documentos. Como referência a este grande movimento, citamos, por exemplo, o deslocamento de contingentes do Exército do sul para o norte do país, bem como a criação do Comando Militar do Norte. Para compormos um patamar mínimo do conceito de política de defesa, entendemos que ela seja o aspecto específico das políticas de governo e de Estado brasileiras que pretende repelir ou dissuadir ameaças externas a território e sociedade, especialmente no atendimento aos princípios constitucionais de suas relações 
internacionais quando à independência, autodeterminação, defesa da paz e igualdade frente a outros Estados (BRASIL, 1988, art. $4^{\circ}$ ). Entendemos que o PCN, sendo uma política voltada para a defesa, mas também para a infraestrutura civil de parte da região amazônica, ganha novo sentido neste movimento, o que será apresentado a seguir, especialmente nos fatores relacionados ao espaço, foco deste artigo.

A PDN de Fernando Henrique Cardoso, pela primeira vez em documento estratégico sobre a defesa, afirmou que esta atividade é voltada ao meio externo ao Estado ${ }^{1}$. Assume-se a inserção do país em um contexto que reconhece as escalas global e regional das relações internacionais, com ênfase generalista a recursos físicos do país que poderiam atrair a cobiça internacional. A guerra de conquista é rejeitada como diretriz de política externa, afirmam-se o perfil majoritariamente diplomático da projeção internacional do Brasil, e o apoio ao desenvolvimento e à integração nacional. Chamamos a atenção para as diretrizes estratégicas presentes no documento, que assumem a tarefa de "proteger a Amazônia brasileira, com o apoio de toda a sociedade e com a valorização da presença militar", priorizando "ações para desenvolver e vivificar a faixa de fronteira, em especial nas regiões norte e centrooeste", e, por fim, conservando uma "mentalidade de Defesa Nacional" (BRASIL, 1996, ps. 04-06, 09-11).

A PDN lançada por Luiz Inácio Lula da Silva em 2005 foi a primeira que distinguiu oficialmente os sentidos de segurança e defesa em documento fundamental da área. Seu contexto era de expectativas do cumprimento de campanha eleitoral de aumento de investimentos e atividades, e de superação de um quadro inicial de ausência de receitas. Além disso, houve turbulências na manutenção de ministros à frente da pasta da Defesa, que se estabilizou naquele ano, com a indicação do vicepresidente, José Alencar, para comandá-la. Em adição à PDN, no período, foram lançadas a Política de Defesa Nacional e a Política Nacional de Indústria de Defesa (PNID) e Sistemática de Planejamento Estratégico de Defesa (SISPEM), cujo objetivo era dinamizar novas organicidade e diretrizes da política de defesa.

$\mathrm{Na}$ PDN de 2005, referências são feitas à Amazônia como área de atenção, colocando-a como um dos pilares estratégicos brasileiros. Além do reforço do conceito

\footnotetext{
${ }^{1}$ Para um aprofundamento sobre a Amazônia como parte da política de defesa brasileira, bem como seu caráter de novidade ou permanência na história do Brasil, ver o artigo de Shiguenoli Miyamoto (2000).
} 
de presença militar, há uma declaração expressa do papel da defesa na "efetiva ação do Estado no desenvolvimento socioeconômico e ampliação da cooperação com os países vizinhos, visando à defesa das riquezas naturais e do meio ambiente" (BRASIL, 2005, item 6.13).

O PCN, sendo retomado a partir de 2005, tem registradas suas Diretrizes Estratégicas em portaria ministerial em 2007. No documento, podemos acompanhar mudanças e continuidades, como a ampliação da área de abrangência territorial do programa, anteriormente baseadas quase que exclusivamente nas fronteiras, o que é justificado ao "agravamento de certas tendências" no contexto amazônico. A área abrangida pelo programa inclui, a partir de então, Acre, Amapá, Amazonas, Maranhão, Matogrosso, Matogrosso dos Sul, Pará, Rondônia, Roraima e Tocantins. Nos aspectos estratégicos e de defesa, o documento afirma haver um esvaziamento geográfico de certas áreas do território, além de perceber haver "novos e perversos fenômenos sociais" dos quais as populações locais deviam ser defendidas. Há uma divisão mais clara de uma vertente militar e uma vertente civil do programa, sendo que a segunda é chamada de Dimensão de Apoio às Ações de Governo na Promoção do Desenvolvimento Regional. Seu objetivo seria "desenvolver infraestrutura básica nos municípios da região abrangida pelo Programa", assumindo compromisso com a integração nacional e o desenvolvimento socioeconômico. (BRASIL. MINISTÉRIO DA DEFESA, 2007).

O documento mencionado acima foi elaborado para servir como guia para representantes e gestores públicos de municípios e estados situados na área de cobertura do PCN. Ecoando padrões de descrição e detalhamento orçamentários praticados desde 2000, ainda no período Fernando Henrique Cardoso, quando começaram a ser criados os planos plurianuais como ferramentas de gestão e transparência, as diretrizes do Programa aumentaram o rol de atividades por ele apoiadas, especialmente na área civil. Acompanhando os relatórios orçamentários de atividades e obras por ele executadas, é possível ver que englobam escolas, equipamentos públicos de lazer e esportes, mercados populares, feiras cobertas, matadouros de animais, depósitos de grãos e veículos para órgãos públicos.

O ano de 2007 foi um divisor de águas para a gestão do Ministério da Defesa, responsável pelo PCN. Um sinal importante do que se afirma foi a indicação de Nelson Jobim para chefiar a pasta. Analistas deste evento afirmam que isso buscava 
solucionar alguns problemas, como a dificuldade de ministros civis chefiarem os militares, a reorganização da aviação civil após dois grandes desastres aéreos e organizar os investimentos em defesa que passaram a crescer no segundo mandato de Lula da Silva (OKADO, 2012; LIMA, 2015; SAINT-PIERRE; WINAND, 2010). Dois marcos da gestão Jobim à frente do Ministério da Defesa foram a recriação do EstadoMaior Conjunto das Forças Armadas (EMCFA), em 2009, e o lançamento da Estratégia Nacional de Defesa (END), em 2008.

A END tinha por objetivo materializar aquilo que havia sido lançado em linhas mais abrangentes pela PDN, de 2005. Além de representar um aprofundamento institucional da organização da atividade de defesa brasileira, procurou dar cabo de situar em termos programáticos os gastos crescentes na área. Em relação ao que nos interessa, quanto ao espaço amazônico e suas relações sociopolíticas com o Estado brasileiro, permanecem as diretrizes da PDN e as diretrizes estratégicas do próprio PCN. É importante, ademais, destacar que o programa passou a contar com maior aporte de recursos, com ênfase em gastos em sua área civil.

$\mathrm{Na}$ área da defesa, o governo Dilma Rousseff chegou em 2011 com a marca da continuidade. Além de ser ex-ministra de seu antecessor no cargo de presidente, no Ministério, manteve Nelson Jobim. Esse fato, acompanhado de uma análise mais ampla de alguns autores como Lessa e Cervo (2014), fez com que o governo Rousseff, no campo das relações internacionais e da segurança internacional, fosse visto como declinante em termos de projeção política. A posição sistêmica do país, herdada do governo Lula, estaria passando por uma crise de gerenciamento (LESSA; CERVO, 2014, ps. 141, 147-149). Uma referência adicional pode ser a leitura de Cornelet (2015), que viu o governo Rousseff como uma contenção na continuidade. Os principais programas de compra de equipamentos e financiamento de infraestrutura foram mantidos. Mesmo quando houve a troca do Ministro da Defesa, em agosto de 2011, Celso Amorim havia sido um quadro do governo Lula, um indicativo adicional de continuidade (BERTAZZO, 2012, p. 816).

No ano de 2012, Dilma Rousseff, seguindo lei promulgada em 2010, lançou o Livro Branco da Defesa Nacional (LBDN), com Amorim à frente da pasta da Defesa. O Livro Branco é importante para a compreensão do PCN como um programa de Estado e de governo porque foi neste documento estratégico que recebeu a classificação de Programa Social da Defesa (PSD). Essa compreensão e locus 
institucional permanecem até os dias de hoje, tendo resistido ao processo de impeachment, ao governo Michel Temer e o primeiro ano do governo Jair Messias Bolsonaro, como se pode observar na comunicação institucional do Ministério da Defesa pela internet.

Os PSD, tal como expressos nas duas versões do LBDN, tanto do governo Rousseff, lançado em 2012, quanto de Temer, aprovado pelo Congresso Nacional em 2017, são definidos igualmente. São definidos como "dispositivos e programas cuja implementação e aplicação contribuem para que haja um aumento de participação social em assuntos de defesa e segurança” (BRASIL, 2012, p. 168). Os programas estão inseridos, também em ambas as versões do LBDN, em uma seção intitulada Defesa e Sociedade. Nesta seção, os governos mencionados invocam as transformações sociais, políticas e tecnológicas da atualidade com impactos nas relações internacionais, na segurança e na defesa, afirmando a necessidade de uma resposta de alto nível a esses desafios. (BRASIL, 2012, p. 167; BRASIL, 2017, p. 131).

Entendemos que o Livro Branco, em suas duas edições, percebe haver desafios para a segurança e a defesa do Brasil. Em geral, a resposta a esse quadro deveria melhorar as relações entre a sociedade e a estrutura de defesa do país, e os PSD seriam um dos vetores de aumentar a participação social na área. 0 entendimento sobre o que seria participação é que fica pouco explicado pelos documentos, podendo estar associado a uma relativização negativa do que participar significa. Fazendo um panorama sobre os PSD, pode-se ver que a sociedade brasileira, representada pelos públicos atendidos pelos programas (população de estados e municípios da Amazônia, ex-recrutas do Serviço Militar Obrigatório, localidades carentes de desenvolvimento humano e infraestrutura, crianças carentes de educação para o esporte), é vista como objeto das políticas públicas, não como sujeito. Há um entendimento lasso de participação.

O PCN, tal como retratado em ambos os livros brancos, de 2012 e 2017, reforça a percepção que assumida no parágrafo anterior. É apresentado como uma política que busca "aumento da presença do Estado em uma área ao mesmo tempo carente e sensível, contribuindo para a defesa e a integração nacionais" (BRASIL, 2012, p. 169; BRASIL, 2017, p. 132). O programa conta com financiamento direto pelo orçamento, colocado sob responsabilidade do Ministério da Defesa, mais verbas de 
emendas parlamentares do legislativo nacional, estadual e municipal da área geográfica que abrange.

Uma diferença na abordagem do PCN pede discussão específica. No LBDN de 2012, afirma-se que o PCN transcenderia uma visão exclusiva da Amazônia alvo apenas de políticas de segurança e defesa numa acepção limitada. É feita uma referência a seu momento de fundação, em 1985, quando era destinado a "promover a ocupação e o desenvolvimento ordenado e sustentável da região ao norte do rio Amazonas". Sua nova versão, apresentada no LBDN, seria "intergovernamental e intersetorial, que envolve diversas agências estatais de considerável alcance social para os brasileiros" (BRASIL, 2012, p. 169). Na versão de 2017, é omitida a menção ao alcance social do programa, afirmando seus elementos intergovernamentais e multidisciplinares (BRASIL, 2017, p. 132).

A viabilização de fundos para o PCN obedece ao processo orçamentário padrão do Estado brasileiro. São previstos nos planos plurianuais, incluídos na Lei de Diretrizes Orçamentárias (LDO) e na Lei Orçamentária Anual (LOA). A seguir, apresentamos uma tabela que reúne dados consolidados na LOA entre os anos 2003 e 2018, para que se avalie o nível de atenção recebido pelo PCN no orçamento público em cada governo reportado. Informações sobre o gasto público em períodos anteriores não obedeciam a esse formato, por isso não estão incluídos. É importante informar ainda que, desde que os valores atribuídos ao programa chegaram aos três dígitos na casa dos milhões, a maior parte dos recursos é voltada para infraestrutura e serviços da área civil. O objetivo de trazermos esse material é poder avaliar o grau de privilégio orçamentário conferido a ele, como indicativo do envolvimento dos planos governamentais e de sua ação sobre o espaço amazônico a partir das características conceituais do PCN.

\begin{tabular}{|ccc|}
\hline $\begin{array}{c}\text { Tabela 1 } \\
\text { (LOA) para o Programa Calha Norte }\end{array}$ \\
\hline Ano & Valor (R\$) & $\begin{array}{c}\text { Média do } \\
\text { Quadriênio (R\$) }\end{array}$ \\
\hline 2003 & 42.445 .611 & \\
2004 & 67.327 .280 & 134.249 .600 \\
2005 & 235.694 .311 & \\
2006 & 191.531 .197 & \\
2007 & 455.021 .000 & \\
2008 & 303.978 .713 & 346.480 .626 \\
2009 & 253.570 .000 & \\
\hline
\end{tabular}




$\begin{array}{ccc}2010 & 373.352 .792 & \\ 2011 & 484.951 .546 & \\ 2012 & 400.596 .000 & 527.999 .653 \\ 2013 & 779.710 .310 & \\ 2014 & 446.740 .755 & \\ 2015 & 956.868 .050 & \\ 2016 & 558.310 .664 & 620.571 .164 \\ 2017 & 531.940 .918 & \\ 2018 & 435.165 .022 & \end{array}$

Fonte: Câmara dos Deputados. Disponível em: <https://www2.camara.leg.br/orcamento-da-uniao/leisorcamentarias/loa>. Elaboração própria.

${ }^{*}$ Houve mudanças na apresentação da LOA no processo legislativo no período estudado. Até 2011 , a previsão orçamentária era apresentada com rubrica única para o PCN. A partir de 2012, foram três: Desenvolvimento Sustentável da Região do Calha Norte, Implementação de Infraestrutura Básica nos Municípios da Região do Calha Norte e Adequação da Infraestrutura dos Pelotões Especiais de Fronteira da Região do Calha Norte. O total anual desse período foi obtido por soma do autor.

Chamamos a atenção, na tabela acima, para o progressivo aumento no gasto público com o PCN, com base nas médias quadrienais. Além disso, informamos que os relatórios da Câmara dos Deputados, entre 2012 e 2018, facilitaram a diferenciação dos gastos com o componente militar e civil do programa, e aqui registramos que, nesse período, a média anual com o primeiro foi de 15.153 .451 reais. Ao projetarmos a diferença nas previsões orçamentárias, percebemos que se fortaleceram duas componentes do programa. A primeira é sua característica de obras e serviços essencialmente civis, que receberam significativamente a maior parte dos recursos. $A$ segunda foi o reforço à visão que se tem do desenvolvimento regional, como dependente da intervenção direta da União e pelo instrumento específico que a empreende, o Ministério da Defesa.

Com base no que se apresentou nesta seção, entendemos um elemento forte de continuidade de um programa governamental de 35 anos, marcado por uma visão conceitual pautada no binômio segurança e desenvolvimento, que pode ter mudado de abordagem, mas não de embasamento. O ambiente amazônico é marcado por conceitos como o de carência, rudimentarismo, vazio, separação do território nacional e inércia. Estes conceitos se encontram literalmente descritos nos documentos fundantes do PCN. O último conceito parte de uma interpretação particular, elaborada a partir da oposição de uma ação pretendida pelo poder público: a vivificação. O vazio e a inércia percebidos são fontes de preocupação por estarem acompanhadas de uma percepção de vizinhança insegura por outros países amazônicos.

Naquilo que se modificou ao longo do histórico institucional do PCN apresentado aqui, percebemos que seu componente militar passou a contar com a 
concorrência de outros programas da defesa, como o SIPAM/SIVAM e a própria redistribuição de contingentes militares sobre o território amazônico. Embora não possamos apontar uma relação de condicionalidade entre essa concorrência na área militar, é importante chamar a atenção para a hipertrofia do elemento civil do programa, claramente demonstrado pelos gastos públicos. Isso mostra forte atribuição de responsabilidade e de disponibilidade orçamentária ao Ministério da Defesa para investir nas ações e obras civis para a Amazônia. Esse incremento é notável especialmente a partir de 2005, a partir do primeiro mandato de Lula da Silva, e se observa um incremento a cada mandato sucessivo.

\section{As políticas para a Amazônia como prática espacial}

O PCN é um importante vetor de recursos financeiros para municípios e estados amazônicos para a realização de obras e serviços públicos variados, de vertentes militar e civil. Como ora exposto, a partir de 2012, seu enquadramento como Programa Social da Defesa institucionalizou a ênfase em sua vertente civil. De acordo com um conjunto de leis regulamentares ${ }^{2}$, o Ministério tem a atribuição de coordenar a missão das Forças Armadas, delimitadas pela Constituição em torno da defesa nacional, da garantia dos poderes constitucionais, e a pedido de algum dos últimos, da lei e da ordem (BRASIL, 1988, art. 142).

$\mathrm{O}$ questionamento deste artigo situa-se em afirmar uma condicionante para a atribuição ao Ministério da Defesa da responsabilidade de financiar e acompanhar obras e serviços civis e ordinários na Amazônia, sendo que isso foge a seu desenho institucional. Exploraremos linha de argumentação em torno de apontar a persistência da política de Estado do Brasil a partir de uma lógica de conquista territorial, por meio da qual se busca justificar e produzir o próprio Estado.

O chamariz para a investigação sobre o conceito de espaço, o meio amazônico e a especificidade da construção institucional do PCN veio das considerações da geógrafa Bertha Becker. Em diversos trabalhos, a pesquisadora afirma que, ao fazer

\footnotetext{
${ }^{2}$ O conjunto de lei abrange a Lei Complementar $n^{\circ}$ 97, de 9 de junho de 1999, que organiza, prepara e emprega as Forças Armadas. O Decreto no 5.484, de 30 de junho de 2005, estabelece a posição de coordenação do Ministério da Defesa. A Lei Complementar no 136, de 25 de agosto de 2010, define as atribuições do Ministro da Defesa, além de criar o Estado Maior Conjunto das Forças Armadas (EMCFA).
} 
política para a Amazônia, o Estado brasileiro produz o seu próprio espaço (BECKER, 2001; BECKER, 2005; BECKER, 2009). O embasamento de Becker é o filósofo Henri Lefebvre, e na interpretação que a geógrafa fez de seu pensamento, afirma que "após a construção do território, fundamento concreto do Estado, este passa a produzir um espaço político - o seu próprio espaço - para exercer o controle social, constituído de normas, leis, hierarquias." (BECKER, 2001, p. 137).

Neste artigo, o PCN é visto como um dos vetores da produção do espaço político pelo Estado brasileiro e que carrega traços institucionais da relação entre 0 governo federal e a agência governamental que a empreende, o Ministério da Defesa. Em sua seção anterior, procuramos sintetizar, da melhor maneira possível, a percepção oficial do meio amazônico, tanto ambiental quanto socialmente, pelos governos e via ministério, desde quando fundado.

Agora, nos aprofundaremos nas categorias conceituais de Lefebvre para apontar quais delas estão presentes nas características gerais do Programa e em suas principais ações. As obras trabalhadas neste artigo são o livro A produção do espaço, publicado originalmente em 1974 (LEFEBVRE, 1991), e o ensaio O Estado, publicado originalmente em 1978 (LEFEBVRE, 2009).

Uma das características fundamentais do conceito de espaço de Lefebvre é o desprendimento da materialidade geométrica, que o define como vazio. Há diversos conceitos de espaço, mas observamos haver no mínimo dois: um associado ao mundo natural, geométrico, euclidiano, e outro, invocado por Lefebvre como o espaço social. As definições do espaço social podem variar tanto quanto as percepções filosóficas do humano, numa revisão feita pelo autor em torno de Aristóteles, Descartes, Leibniz, Espinosa e Kant. A noção de espaço lefebvriana tem assumida genealogia com o último, que a percebia como uma categoria subjetiva (LEFEBVRE, 1991, p. 1-2).

A discussão teórica de Lefebvre é bastante rica em referências a outros campos do conhecimento que têm visões particulares sobre o espaço, passando pela linguística, semiologia, sociologia e a política. Para circunscrever a discussão a este trabalho, evocamos algumas passagens mais específicas, tal como a percepção de Michel Foucault, que entenderia, de acordo com, Lefebvre, que o espaço seria "o lugar no qual o sujeito toma posição" (LEFEBVRE, 1991, p. 4) no ato de constituir o seu saber. A questão de quem é o sujeito, portanto, se torna central para entender o 
espaço e sua produção. A formação ideológica, científica, histórica de dado ator político seria determinante, sendo ele um ator individual ou coletivo.

Há uma crítica severa à identificação automática entre o espaço social e o espaço natural: essa identificação é vista pelo autor como um abismo (Idem, p. 6). De acordo com ele, a ciência do espaço deve contemplar o uso político do conhecimento sobre ele próprio, com uma ideologia associada, bem como uma utopia técnica (no melhor dos casos) (Idem, p. 9). Em outras palavras, o sujeito político, particular ou coletivo, se constitui intelectualmente e em sua relação com o meio, justifica o estado de coisas com sua percepção da realidade e a modifica materialmente em busca de adaptações, ganhos e melhoras para si.

O conceito de hegemonia gramsciano é trazido como um dos elementos que compõem as práticas espaciais. Lefebvre, que expõe seu pensamento a partir da escala macro, dá exemplos associados ao capitalismo e a hegemonia que as burguesias, nacional ou internacional, exercem sobre as classes trabalhadoras (Idem, p. 10). Buscamos evidenciar que difundir uma visão de mundo, categorias formais de descrever a realidade, valores, dentre outros elementos ideacionais, por um sujeito sobre outro é um ato hegemônico. Esse ato é pleno e efetivo quando a transmissão é feita de tal forma que o segundo faz uso desses elementos emulando alguma propriedade sobre eles.

O conceito de espaço também está atrelado ao conceito de força, tanto no sentido físico, quanto no social. A força, dentro do espaço, tem a ver com o estabelecimento de limites e de formas. Essa visão, que tem inspiração nietzschiana, permite a Lefebvre dizer que onde há espaço, há existência (Idem, p. 22). Como a visão sobre espaço na obra de Lefebvre é relacional, é importante reforçarmos que, sempre haverá espaços diferentes na medida em que seres diferentes estejam em interação.

O pensamento de Lefebvre está situado em um tempo histórico. A maior parte de seus escritos sobre o tema da produção do espaço é da década de 1970, momento em que a globalização era um fenômeno novo e os processos que engendra tinham características que no presente se apresentam de outra forma. Por isso, é possível encontrar referências no texto que aqui revisamos, original de 1974, de que o Estado estivesse ainda se consolidando em escala mundial, quando na década de 1990 se 
escreveram tantas obras sobre o fim do Estado soberano ou moderno (WEBER, 1995; STRANGE, 1996; KRASNER, 1999; CZEMPIEL, ROSENAU, 1992).

Na obra O Estado (LEFEBVRE, 2009), publicada originalmente em 1978, Lefebvre descreve de maneira simplificada o processo de instalação do espaço estatal, diferenciando-o de outras modalidades de espaço. Além disso, o filósofo ainda expõe tipos de espacialidade que cada ator social ou político pode compor. De acordo com ele, o Estado se vincula ao espaço por meio de três formas. A primeira seria a criação do território nacional, com sua malha de integração: redes, circuitos e fluxos. A segunda seria o espaço social, um edifício artificial de instituições, leis, símbolos, convenções e língua, criando um conjunto de hierarquias encadeadas. A última é o espaço mental, baseadas nas representações que as pessoas elaboram do Estado (LEFEBVRE, 2009, p. 224-225).

As temporalidades da construção do espaço do Estado podem ocorrer de maneiras paralelas e concorrem ainda com as temporalidades de outros atores sociais e políticos com os quais interaja. Considerando que, onde houver espaço haverá também existência, força e energia, "a racionalidade do Estado, de suas técnicas, planos e programas, provoca oposição. A violência do poder é respondida pela violência da subversão" (LEFEBVRE, 1991, p. 23). O autor, também aponta projetos, ciências aplicadas e o conhecimento como práticas do poder (Idem, p. 50).

O espaço do Estado convive com as espacialidades do capitalismo contemporâneo, que são abstratas. Os mercados financeiros, especulativos, de commodities e as operações de concorrência, negociação, oligopolização que ocorrem em seu interior são todos elementos deste espaço (Idem, p. 53). As temporalidades e práticas espaciais do Estado e do capitalismo podem ser cooperativas ou conflituosas, a depender do contexto histórico (LEFEBVRE, 2009, p. 228).

Ao olharmos para a instauração do Estado, tanto em sua componente histórica quanto conceitual, percebemos algumas questões a partir da leitura de Lefebvre. Em primeiro lugar, o Estado como ente político e o território se relacionam de uma maneira em que são constituídos mutuamente (Idem, p. 228). Em nossa época, a representação do espaço ocorre por meio das linguagens técnicas e científicas, por conta dos laços com a modernidade e o capitalismo. O Estado, portanto, tende a ser visto e representado a partir de uma descrição de sua organização política, de como 
viabiliza suas ações por meio das instituições e organicidade que lhe é constitutiva. A organicidade do Estado moderno, por sua vez, se utiliza dessas ferramentas para separar grupos em conflito social, situando alguns deles em guetos, hierarquiza os lugares com base em relações de poder e controla o sistema todo que é criado (Idem, p. 243).

Bertha Becker, por beber diretamente na fonte dos escritos lefebvrianos, é uma ponte evidente entre essas considerações mais gerais e o espaço amazônico. Buscaremos centralizar nossa discussão na escala regional desse conceito, com ênfase na área abrangida pelo PCN. Em artigo publicado em 2001, Becker percebe a ocupação da Amazônia pelo Estado brasileiro com forte herança da colonização, que marcou a história local com uma economia de fronteira. Esse padrão de atividade econômica percebe o meio natural como fonte inesgotável de riqueza e recursos para a movimentação da atividade econômica. O controle do território é fundamental para garantir os fluxos e ele é feito por meio de pontos avançados, que serviriam como cabeça de ponte para a consecução de tal objetivo (BECKER, 2001, p. 135).

O histórico de ocupação da Amazônia também criou duas vertentes de desenvolvimento socioeconômico diferentes, por vezes próximos e por vezes distantes. Um deles tem natureza exógena, fortemente integrado à economia de fronteira, e outro tem natureza endógena, firmado em torno das microrregiões da Amazônia, populações ribeirinhas, indígenas, extrativistas, etc. Cada um deles tem um tipo de integração no espaço, sendo que o primeiro é fortemente vinculado aos meios tradicionalmente promovidos pelo Estado, como estradas, pontos de apoio de abastecimento e incentivos à instalação de aparelhos urbanos e industriais. $O$ segundo tem uma origem nuclear e insulada, mas que posteriormente contaria com a base de redes locais, nacionais e internacionais de financiamento, transmissão de dados, implementação de programas, técnicas e atores sociopolíticos (Idem, p. 136).

O PCN, fundado em 1985, é o último dos programas governamentais fundados dentro do paradigma de desenvolvimento exógeno defendido por Becker. A principal característica que podemos apontar no programa que corrobora o ponto de vista da geógrafa são seus primeiros focos, os Pelotões Especiais de Fronteira, e obras de construção civil como pontes, aeródromos e estradas que funcionam como pontos fixos onde assentar as linhas de integração. Outros elementos fundamentais presentes no programa que o vinculam conceitualmente a esse padrão de ocupação 
são a indução pública de investimentos, ocupação humana e a superposição de territórios federais sobre os estaduais (Idem, p. 137-139).

O PCN, como afirmado anteriormente, teve um período de baixa atividade orçamentária e executiva, notadamente na década de 1990. O movimento de retomada de dinamismo do programa se iniciou no fim do segundo mandato Fernando Henrique Cardoso com a instauração dos Planos Plurianuais (PPAs) e o Programa Avança Brasil. Os PPAs e os programas estratégicos do orçamento público nacional, como o Avança Brasil, são vistos por Becker como dinamizadores dos vetores exógenos do desenvolvimento da Amazônia (Idem, p. 149-150). A diferença de contexto do PCN dentre políticas públicas para a região antes de 1985, no intervalo 1985-1989 e a década de 1990 está marcada pela concorrência de outras políticas macro regionais, como o SIPAM/SIVAM e as demarcações de terras indígenas, zonas extrativistas e ambientais.

Embora cronologicamente os escritos de Becker trabalhados acima não possam ser aplicados aos governos Lula da Silva, Rousseff e Temer, na segunda seção deste artigo mostramos o aumento substantivo do orçamento do PCN. Isso ocorreu no contexto de grandes movimentos de integração e desenvolvimento, com os Programas de Aceleração do Crescimento I e II. Adicionamos ainda a articulação sul-americana capitaneada pelo Brasil IIRSA/COSIPLAN. Entendemos que a sinergia entre os PPAs e os programas de desenvolvimento econômico esteve presente no período estudado por Becker e permaneceu até o fim do período analisado por esse artigo. Além deles, os vetores internacionais e extrarregionais do modelo exógeno de desenvolvimento também estiveram presentes em todo o período.

\section{As práticas espaciais no Programa Calha Norte}

Como apresentado na segunda seção deste artigo, o PCN passou por uma série de transformações, que resumimos em quatro etapas. A primeira é sua própria criação, que recebeu maior atenção para os aspectos militares e mais urgentes no campo civil. A segunda foi a de paralisação e baixa atividade orçamentária, durante a década de 1990. A terceira foi a de estudos, reelaboração e retomada, entre 2000 e 2005, com dois momentos de alteração da abrangência territorial do programa, para além da calha norte dos rios Amazonas e Solimões. Até 2018, temos a fase de 
expansão do programa e seu enquadramento institucional como Programa Social da Defesa.

Ao iniciarmos a contraposição entre a leitura de Lefebvre e a análise da progressão institucional do PCN, percebemos uma prática espacial presente em todas as suas fases: a de produção do Estado (e consequentemente do governo) a partir das ideias de precariedade e de vazio de poder. O território do Calha Norte, muitas vezes representativo da visão geral da política institucional sobre a Amazônia, é visto como carente. O vazio de poder, por sua vez, tem duas faces, uma de natureza política interna e outra ligada ao meio internacional. Na política interna, a imagem se presentifica na expressão "ausência do Estado". No campo internacional, o discurso presente é o da segurança das fronteiras e a concorrência do crime transnacional com as agências estatais da segurança e da defesa.

A prática espacial é relacional. Dessa forma, quando a descrevemos, é produtivo avaliar os eventuais sujeitos e os objetos em torno de sua efetivação. A política estatal de corrigir o apregoado vazio de poder e a precariedade tem como sujeito um ator que ao mesmo tempo em que se coloca como o corretor desses problemas, escamoteia suas influências sobre aquilo que pretende corrigir. $O$ ator estatal, neste caso, é complexo e tem múltiplas agências. O PCN nasceu como um programa diretamente ligado à Presidência da República, mas com traços fortes do pensamento militar, da geopolítica e da segurança internacional. A permanência no elemento discursivo da retórica do vazio de poder, da precariedade e do padrão militarizado da resposta em todo o período de análise aponta para um elemento de continuidade.

A notável tensão existente na fase de criação do PCN entre a política estatal de ocupação e desenvolvimento do norte amazônico e as populações indígenas também é matéria de reflexão a partir do pensamento lefebvriano. Esse conflito revela a interação de espacialidades, práticas espaciais e o tema do espaço natural. As espacialidades em conflito são a dos sujeitos indígenas e o sujeito assumido pela política pública. Suas idiossincrasias são diferentes e a última se coloca em posição de integrar os indígenas à "comunhão nacional". Disso decorre outro elemento conflitivo, a prática espacial pouco diversa. A maneira dos povos indígenas habitarem e se desenvolverem no espaço amazônico é vista como ameaça pelo PCN em suas fases iniciais. Posteriormente, eles são incluídos nos grupos sociais carentes de 
atenção pelas políticas públicas, o que justificaria o crescimento do componente civil do programa. O espaço natural (des)aparece como aquele que precisa ser ocupado pelo Estado, associado a rudimentarismos ou ausência do elemento humano, uma vez que sua representação como natural traz essas características como premissa.

A tensão entre a chamada política indigenista e o PCN é umas das nuances de uma questão geral que é a interação de modelos de desenvolvimento concorrentes, endógeno e exógeno. A situação foi trazida neste texto por Bertha Becker, mas o elemento lefebvriano subjacente é o poder criador e modelador das práticas espaciais. Lefebvre afirmou que onde há espaço, há força e energia, entendidas num sentido amplo, englobando o espaço físico, social e o mental. Além dos grupos sociais indígenas, das cidades amazônicas, populações ribeirinhas e extrativistas praticam seus modos de vida e existência dentro e a partir do espaço. Essas práticas espaciais são chamadas de endógenas. A prática espacial do Estado brasileiro tem como vetores práticos obras e serviços de infraestrutura civil e militar e fazer parte de um conceito exógeno de desenvolvimento. Os referenciais de endogenia e exogenia levantados têm como ancoragem a Amazônia. As interações de tais modelos ocorrem em planos diversos, seja na transformação do ambiente físico, nas relações sociais (incluindo aí a própria constituição dos sujeitos, referente ao espaço social) e os campos da ciência e da cultura política (referentes ao espaço mental).

O PCN é um programa que atravessou todos os governos do intervalo temporal entre 1985 e 2018. Em nossa percepção, como exposto acima, teve quatro fases em que seu orçamento variou significativamente e também o dinamismo de seus componentes militar e civil. Guardadas as diferenças entre as fases nesse quesito, a permanência do programa traz um elemento importante ao Estado brasileiro como sujeito de práticas espaciais, tanto em termos de sua organicidade quanto da relação interna a ela. A criação do programa, os planos de médio prazo relacionados a ele, como os planos plurianuais, e as leis orçamentárias, foram estabelecidos a partir da interação entre as Forças Armadas e o governo, vinculados fortemente à presidência. Essa característica vincula uma série de políticas importantes para a sociedade brasileira, e em especial para a amazônica, a um privilégio do elemento militar. É mister que se realce o fato, especialmente porque o PCN tem um componente civil, que se tornou o mais volumoso, especialmente a partir de sua ampliação e reposicionamento institucional, a partir dos primeiros anos da década de 2000. Dessa 
forma, a política espacial para a porção amazônica abrangida pelo programa se investe de militarismo, ao mesmo tempo em que a política militar se torna mais difusa do que a defesa nacional.

Um desdobramento adicional do que acabamos de afirmar é a sobreposição do território federal aos estaduais e municipais e as redes de barganha política que se criam a partir do PCN. Becker (2009) afirma que a sobreposição federal é uma das características das políticas de desenvolvimento para a Amazônia do período militar. O PCN é visto por ela como o último programa governamental concebido ainda sob esse paradigma. Mesmo com as mudanças que se observam no histórico institucional do programa, percebe-se a continuidade desse elemento, dotando a prática espacial nele presente de um paralelismo com aquelas dos poderes locais, como estados e municípios, mas também outros atores, como empresas, grupos sociais, ONGs, dentre outros. Os executores do PCN compõem uma rede de barganha política com estados e municípios porque estabelecem consórcios para a realização de obras e serviços. Com as empresas, estabelecem relações de contratação e fiscalização. Os demais atores se fazem presentes por uma série de contextos, como licenciamento ambiental, sendo beneficiários de obras e serviços promovidos pelo programa, etc.

Uma percepção final que apresentamos nesta seção concerne à coincidência dos movimentos de expansão orçamentária e de especialização da defesa com a progressão do PCN a partir da década de 2000. A expansão orçamentária do Ministério da Defesa, em geral, passou a acontecer a partir de 2003, se tornando definitivamente expressivo a partir de 2007. A especialização da política de defesa brasileira, expressa por meio dos documentos estratégicos, como as PDNs, a END e os LBDNs, entre 1996 e 2016, tiveram como papel estabelecer conceitos e limites das políticas públicas da segurança, da defesa, apresentar orçamento, organogramas e transparência, e definir as ações subsidiárias da área. O PCN, como mostramos anteriormente, esteve inserido em ambos os movimentos. Na questão orçamentária, foi incrementado, e especialmente em seu componente civil. No campo institucional, a hipertrofia de seu componente civil trouxe impactos e o programa passou a ser um Programa Social da Defesa, a partir de 2012. O que argumentamos a partir do observado é que a especialização das estruturas de defesa do Estado brasileiro não fez com que seus órgãos deixassem de ser envolvidos em políticas civis que fogem ao seu escopo, especialmente no espaço amazônico abrangido pelo PCN. 


\section{Conclusões}

O desenvolvimento institucional do Programa Calha Norte, durante os governos estudados entre 1985 e 2018, expressou forte elemento de continuidade quanto a suas práticas espaciais.

Como sujeitos dessa prática, Estado e governo continuaram definindo a região abrangida pelo programa como um espaço à margem do território nacional, sempre em vias de ser plenamente incorporado. Guardadas as devidas ressalvas quanto às diferentes fases de dinamismo do PCN, suas ações tiveram por objetivo aproximar o espaço local dos modelos de desenvolvimento, infraestrutura e contextos sociais do centro político nacional. Contraditoriamente, essa busca por uma coincidência de imagens e desejado padrão de normalidade é feita por meio da gestão pelo instrumento militar, por definição excepcional.

O desenho institucional do PCN, com orçamento próprio e autonomia de planejamento, faz dos órgãos burocráticos da defesa atores políticos regionais e locais, com uma rede de relações diretas com o meio social em que eles estão inseridos. O poder sobre recursos financeiros importantes para estados e municípios da região faz do programa um vetor importante para o estabelecimento de uma relação hegemônica em que elementos do espaço mental, tal como definido por Lefebvre são difundidos. Este espaço mental contém elementos promotores da sobreposição do poder federal sobre o estadual e municipal, da autonomia militar e da justificação da forma estatal como organização política.

Como argumentou Lefebvre, o espaço é um conceito subjetivo e relacional, e ecoando Foucault, entende também que é o lugar em que os sujeitos se posicionam para construir o seu saber, inclusive de si próprios. Entendemos que os sujeitos diversos, individuais e coletivos atendidos pelo PCN, em especial por meio das políticas de naturezas civil, social e de desenvolvimento, tendem a ser inseridos num espaço social que os condiciona a expressões de sujeição direta ao elemento militar quando buscam pelos recursos públicos por ele viabilizados.

\section{Referências}


BECKER, Bertha. Revisão das políticas de ocupação da Amazônia: é possível identificar modelos para projetar cenários? In: Parcerias Estratégicas, v. 6, n. 12, 2001. Disponível em: <http://seer.cgee.org.br/index.php/parcerias_estrategicas/article/view/178>, acessado em 08/07/2020.

. Geopolítica da Amazônia. In: Estudos Avançados, v. 19, n. 53, 2005. Disponível em: <https://www.scielo.br/pdf/ea/v19n53/24081.pdf>, acessado em 08/07/2020.

O governo do território em questão: uma perspectiva a partir do Brasil. In: Parcerias Estratégicas, v. 14, n. 28, p. 33-50, 2009. Disponível em: <http://seer.cgee.org.br/index.php/parcerias_estrategicas/article/viewFile/339/332>, acessado em 15/05/2020.

BERTAZZO, Juliana. Brazilian Security and Defence Policy under president Dilma Rousseff. In: Critical Sociology, v. 38, n. 6, 2012, p. 809-821. Disponível em: $<$ https://doi.org/10.1177/0896920512441634>, acessado em 15/05/2020.

BRASIL. [Constituição (1988)]. Constituição da República Federativa do Brasil: promulgada em 5 de outubro de 1988. 1988. Disponível em: <http://www.planalto.gov.br/ccivil_03/constituicao/constituicao.htm>, acessado em 11 de maio de 2020.

BRASIL. Conselho de Segurança Nacional. Desenvolvimento e segurança na região ao norte das calhas dos rios Solimões e Amazonas. 1985. Disponível em: $<$ https://acervo.socioambiental.org/acervo/documentos/desenvolvimento-e-

seguranca-na-regiao-ao-norte-das-calhas-dos-rios-solimoes-e>, acessado em 6 de maio de 2020.

BRASIL. Decreto no. 5.484, de 30 de junho de 2005. Aprova a Política de Defesa Nacional e dá outras providências. 2005. Disponível em: <http://www.planalto.gov.br/ccivil_03/_Ato2004-2006/2005/Decreto/D5484.htm>, acessado em 11 de maio de 2020.

BRASIL. Livro Branco da Defesa Nacional. 2012. Disponível em: <http://www.defesa.gov.br/arquivos/estado_e_defesa/livro_branco/livrobranco.pdf>, acessado em 15/05/2020.

BRASIL. Ministério da Defesa. Portaria normativa no. 1185/SPEAI/MD, de 13 de setembro de 2007. Dispõe sobre as Diretrizes Estratégicas para o Programa Calha Norte ( $P C N)$, do Ministério da Defesa, e dá outras providências. 2007. Disponível em: $<$ http://bdlegis.defesa.gov.br/gerar_html_norma/gerar_html_norma.php?id_norma=1 $414>$, acessado em 12 de maio de 2020.

BRASIL. Ministério da Defesa. Programa Calha Norte. 2020. Disponível em: $<$ https://www.defesa.gov.br/programas-sociais/programa-calha-norte>, acessado em 6 de maio de 2020. 
CORNELET, João Marcelo Conte. A política externa de Dilma Rousseff: contenção na continuidade. In: Revista Conjuntura Austral, v. 5, n. 24, 2014. Disponível em: <oaji.net/articles/2015/2137-1438857367.pdf>, acesso em 15/05/2020.

COSTA SILVA, Marcelle Ivie. Amazônia e política de defesa no Brasil (1985-2002). Dissertação de mestrado em Relações Internacionais, PPGRI San Tiago Dantas, 2004.

CZEMPIEL, Ernest-Otto; ROSENAU, James. Governance Without Government: Order and Change in World Politics. Cambridge: Cambridge University Press, 1992.

DINIZ, Eugênio. Um diálogo de surdos: o Projeto Calha Norte. In: Lua Nova, n. 34, p. 87-116, 1994.

KRASNER, Stephen. Sovereignty: organized hypocrisy. Princeton: Princeton University Press, 1999.

LEFEBVRE, Henri. The Production of Space. Oxford: Blackwell, 1991.

LEFEBVRE, Henri. Space: Social Product and Use Value. 1979. In: State, Space, World: selected essays. Minneapolis: Minnesota University Press, 2009, ps. 185-195.

LESSA, Antônio Carlos; CERVO, Amado Luiz. O declínio: inserção internacional do Brasil (2011-2014). In: Revista Brasileira de Política Internacional. Brasília, v. 57 n. 2, 2014. Disponível em: <http://dx.doi.org/10.1590/0034-7329201400308>, acessado em 15/05/2020.

LIMA, Raphael Camargo. A articulação entre política externa e política de defesa no Brasil: uma Grande Estratégia inconclusa. Dissertação de Mestrado em Relações Internacionais, PPGRI San Tiago Dantas, 2015.

MIYAMOTO, Shiguenoli. A Política de Defesa Brasileira e a Defesa Nacional. In: Contexto Internacional, v. 22, no.2, p. 431-472, 2000.

NASCIMENTO, Durbens Martins. Projeto Calha Norte: Política de Defesa Nacional e Segurança Hemisférica na Governança Contemporânea. Tese de doutorado em Desenvolvimento Sustentável do Trópico Úmido, Universidade Federal do Pará, 2005.

OKADO, Giovanni Hideki Chinaglia. Política externa e política de defesa: uma epifania pendente. Dissertação de Mestrado em Relações Internacionais, Universidade de Brasília, 2012.

PROCÓPIO, Argemiro. A Amazônia Caribenha. Revista Brasileira de Política Internacional, v. 50, n. 2, p. 97-117, 2007.

SAINT-PIERRE, Héctor Luís; WINAND, Érica A. A fragilidade da condução política da defesa no Brasil. In: História. V. 29, no. 02, 2010. 
SILVA, Altiva Barbosa. Geopolítica na Fronteira Norte do Brasil: o papel das Forças Armadas nas transformações socio-espaciais do Estado de Roraima. Tese de doutorado em Geografia Humana, Universidade de São Paulo, 2007.

STRANGE, Susan. The Retreat of the State. Cambridge: Cambridge University Press, 1996.

WEBER, Cynthia. Simulating Sovereignty. Cambridge: Cambridge University Press, 1995. 